JURNAL REFLEKSI EDUKATIKA 8 (2) (2018)

p-ISSN: 2087-9385 e-ISSN: 2528-696X

http://jurnal.umk.ac.id/index.php/RE

\title{
META-ANALISIS PENGARUH MODEL PEMBELAJARAN ROLE PLAYING TERHADAP HASIL BELAJAR IPS
}

\author{
Firosalia Kristin ${ }^{凶}$
}

PGSD Universitas Kristen Satya Wacana

\begin{abstract}
Info Artikel
\section{Abstract}

Sejarah Artikel:

Diterima 6 Mar 2018

Direvisi 13 Mar 2018

Dipublikasikan: Jun 2018

\section{Keywords:}

Role Playing Learning

The purpose of this research was to re-analyze the use of Role Playing model in increasing the learning outcome in social studies subject. The research method wasmeta-analysis. The research began with formulating research problems, then tracing relevant research results to be analyzed. The data was collected by browsing electronic journals through Google Scholar using "learning outcomes", "role playing", and "Social Studies of Primary Education" keywords. The searching result showed that there were 86 articles but only 12 relevant articles from the journal. The data were analyzed using qualitative descriptive analysis. The analysis result showed that Role Play learning model could improve student's learning outcomes from the lowest $1.65 \%$ to the highest $64.32 \%$ and the mean was $23.32 \%$.
\end{abstract}

Model, Social Studies

Outcomes, Meta-Analysis

\begin{abstract}
Abstrak
Tujuan penelitian ini untuk menganalisis kembali penggunaan model pembelajaran role playing dalam meningkatkan hasil belajar IPS. Metode yang digunakan dalam penelitian ini adalah meta analisis. Penelitian diawali dengan merumuskan masalah penelitian, menelusuri hasil penelitian yang relevan untuk dianalisis. Data dikumpulkan dengan menelusuri jurnal elektronik melalui Google Scholar dengan kata kunci "hasil belajar", "bermain peran", "pembelajaran IPS SD". Dari penelusuran itu diperoleh 86 artikel tetapi yang relevan hanya 12 artikel dari jurnal. Data dianalisis dengan menggunakan analisis deskriptif kualitatif. Berdasarkan hasil analisis model pembelajaran role playing mampu meningkatkan hasil belajar siswa mulai dari yang terendah $1,65 \%$ sampai yang tertinggi $64,32 \%$ dengan rata-rata $23,32 \%$.
\end{abstract}

(C) 2018 Universitas Muria Kudus

${ }^{\square}$ Alamat korespondensi:

p-ISSN 2087-9385

Program Studi Pendidikan Guru Sekolah Dasar

e-ISSN 2528-696X

Kampus UMK Gondangmanis, Bae Kudus Gd. L. 1t I PO. BOX 53

Kudus

Tlp (0291) 438229 ex.147 Fax. (0291) 437198

E-mail: firosalia.kristin@staff.uksw.edu 


\section{PENDAHULUAN}

Proses pembelajaran yang baik dan tepat mempengaruhi kualitas pembelajaran. Dalam rangka meningkatkan mutu pendidikan yang bagus harapan yang ingin dicapai adalah pembelajar memahami apa yang dipelajari dan dapat diterapkan di kehidupan yang nyata. Oleh karena itu, guru dituntut memiliki pengetahuan yang inovatif agar dalam proses pembelajaran bukan hanya guru yang aktif tetapi juga siswanya. Dengan demikian proses pembelajaran yang optimal akan terwujud.

Siswa yang kurang paham terhadap materi pelajaran yang disampaikan menjadi salah satu permasalahan dalam proses pembelajaran. Hal tersebut dapat disebabkan dari tidak efektif dan efisiennya proses pembelajaran yang dilakukan oleh guru sehingga hasil belajar siswa cenderung rendah. Jika proses pembelajaran yang dilakukan di dalam kelas hanya bersifat menghafal sebuah informasi tanpa harus berpikir untuk memahami informasi tersebut, maka siswa mengalami kesulitan ketika mendapatkan soal-soal penalaran (Aif dan Rijanto 2017: 372). Hal ini sejalan dengan pendapat Kristin (2016: 91) yang mengatakan bahwa proses pembelajaran dapat berlangsung karena adanya siswa, guru, kurikulum, satu dengan yang lain saling terkait atau saling berhubungan. Siswa dapat belajar dengan baik jika sarana dan prasarana untuk belajar memadai, model pembelajaran guru menarik, siswa ikut aktif dalam proses pembelajaran sehingga siswa tidak merasa jenuh atau bosan ketika mengikuti pembelajaran di kelas.

Ada banyak model pembelajaran yang dapat digunakan guru untuk membantu dalam proses pembelajaran. Salah satu model itu adalah model role playing atau bermain peran. Model pembelajaran role playing merupakan salah satu model yang dapat diterapkan dalam proses pembelajaran di dalam kelas karena model ini menarik bagi siswa, mereka dapat bermain peran sebagai tokoh dalam peristiwa sejarah atau kejadian-kejadian masa lampau. Jika ini diterapkan dalam pembelajaran IPS, maka sangatlah tepat mengingat yang dipelajari di IPS juga terkait dengan kejadian masa lampau bukan hanya tentang lingkungan di sekitarnya. Selain itu model ini dapat meningkatkan keaktifan siswa dalam proses pembelajaran (Suarsana dkk 2013: 4).

Penerapan model role playing atau bermain peran memiliki kesesuaian dengan karakteristik siswa terutama siswa sekolah dasar (Suarsana dkk 2013: 4). Sejalan dengan pendapat Syaodih (dalam Suarsana dkk 2013: 4) bahwa karakteristik anak SD yang pertama adalah senang bermain, kedua yakni senang bergerak. Jadi karakteritik anak SD tersebut mengharuskan guru untuk membuat pembelajaran di kelas yang menyenangkan dan siswa bisa belajar sambil bermain.

Berdasarkan uraian tersebut, maka fokus penelitian ini yaitu apakah penggunaan model pembelajaran role playing dapat meningkatkan hasil belajar IPS jika diterapkan di sekolahsekolah yang berbeda tempatnya?

\section{METODE PENELITIAN}

Penelitian ini menggunakan jenis penelitian meta analisis. Pengumpulan data dilakukan dengan menelusuri google scholar atau google cendikia. Kata kunci yang digunakan dalam penelusuran ini adalah model pembelajaran role playing, hasil belajar, dan pembelajaran IPS. Dari hasil penelusuran diperoleh 86 artikel kemudian diambil 12 artikel yang relevan yang sudah diterbitkan di jurnal online. Dasar pengambilan artikel tersebut adalah adanya data sebelum dan sesudah tindakan dalam bentuk skor. Analisis data yang digunakan adalah deskriptif kualitatif.

\section{HASIL DAN PEMBAHASAN}

Hasil penelitian yang diikutkan dalam penelitian meta analisis ini adalah:

1. Penerapan Metode Bermain Peran Untuk Meningkatkan Aktivitas dan Hasil Belajar Siswa Kelas V Pada Mata Pelajaran IPS Pokok Bahasan Jenis-jenis Usaha Ekonomi Di SDN Ngadiluwih 02 Kediri oleh Zulfa N dan Chumi Zahroulf.

2. Penerapan Metode Pembelajaran Role Playing Untuk Meningkatkan Motivasi Dan Hasil Belajar Siswa Pada Pembelajaran IPS Di Sekolah Dasar oleh Ratna Puspita Dewi dan Ganes Gunansyah.

3. Upaya Peningkatan Hasil Belajar IPS Materi Mempertahankan Kemerdekaan Indonesia Melalui Metode Role Playing Pada Kelas V SD Negeri 02 Wiroditan Kabupaten Pekalongan oleh Sri Utami dan Muhammad Afandi.

4. Penggunaan Metode Role Playing Untuk Meningkatkan Hasil Belajar Ilmu Pengetahuan Sosial Di Sekolah Dasar Negeri Palembang oleh Budiansyah.

5. Upaya Peningkatan Hasil Belajar IPS Melalui Penerapan Metode Role Playing Pada Siswa Kelas III SDN 2 Gedongmulyo Kecamatan Lasem Kabupaten Rembang Tahun 2014/2015 oleh Muslimah. 
6. Pengaruh Penggunaan Model Role Playing Dengan Media Video Terhadap Hasil Belajar IPS (Studi Eksperimen Pada Siswa Kelas V SDN Gondangwetan 1 Pasuruan) oleh Raran Suci Lestari.

7. Penerapan Model Pembelajaran Kooperatif Bermain Peran (Role Playing) Pada Mata Pelajaran Ilmu Pengetahuan Sosial Untuk Meningkatkan Hasil Belajar Siswa Kelas III Di SD Negeri Setragalih Kecamatan Cibogo Kabupaten Subang oleh Eem Sulaemi.

8. Peningkatan Hasil Belajar Siswa Melalui Teknik Bermain Peran Pada Mata Pelajaran IPS Pokok Bahasan Proklamasi Kemerdekaan oleh Rossi Iskandar.

9. Peningkatan Aktivitas dan Hasil Belajar Materi Peristiwa Sekitar Proklamasi Melalui Bermain Peran oleh Rini Meita Indrawati.

10. Meningkatkan Karakter Dan Hasil Belajar IPS Menggunakan Metode Bermain Peran Pada Siswa SD oleh
Achmad Basari, Eko Wahyudi, dan Siti Partini Suardiman.

11. Penerapan Model Pembelajaran Role Playing Untuk Meningkatkan Hasil Belajar IPS Siswa Kelas III SD Negeri 013 Lubuk Kembang Sari Kecamatan Ukui oleh Arleni Tarigan.

12. Pengaruh Penggunaan Model Role Playing Dengan Media Video Terhadap Hasil Belajar IPS (Studi Eksperimen Pada Siswa Kelas V SD Islam AlGontory Tulungagung) oleh Eka Yuliana Sari, Inggrid Bela Suastiaji dan Lintang Permata.

Data yang dipakai dalam penelitian ini masih luas dan banyak sehingga data diolah dengan cara dirangkum dan diambil intisarinya saja kemudian di analisis secara deskriptif kuantitatif dan kualitatif. Hasil analisis model pembelajaran role playing atau bermain peran dapat dilihat pada tabel 1 berikut ini:

Tabel. 1 Hasil Analisis Model Pembelajaran Role Playing atau Bermain Peran

\begin{tabular}{|c|c|c|c|c|c|}
\hline \multirow[b]{2}{*}{ No } & \multirow[b]{2}{*}{ Topik Penelitian } & \multicolumn{4}{|c|}{ Peningkatan Hasil Belajar } \\
\hline & & Sebelum & Sesudah & Gain & $\begin{array}{c}\text { Gain } \\
(\%)\end{array}$ \\
\hline 1 & $\begin{array}{l}\text { Metode Bermain Peran, Aktivitas dan Zulfa N, Chumi Zahroulf } \\
\text { Hasil Belajar IPS }\end{array}$ & 73,2 & 83,8 & 10,6 & 14,48 \\
\hline 2 & $\begin{array}{lllll}\text { Metode Pembelajaran Role } & \text { Playing } & \text { Ratna Puspita } & \text { Dewi, } \\
\text { Motivasi Dan Hasil Belajar IPS } & & \text { Ganes Gunansyah } & \\
\end{array}$ & 66 & 84,2 & 18,2 & 27,57 \\
\hline 3 & $\begin{array}{ll}\text { Hasil Belajar IPS, Metode Role Playing } & \begin{array}{l}\text { Sri Utami, Muhammad } \\
\text { Afandi }\end{array}\end{array}$ & 60 & 69,5 & 9,5 & 15,83 \\
\hline 4 & $\begin{array}{l}\text { Metode Role Playing dan Hasil Belajar Budiansyah } \\
\text { Ilmu Pengetahuan Sosial }\end{array}$ & 71,42 & 77,64 & 6,22 & 8,70 \\
\hline 5 & Hasil Belajar, IPS Metode Role Playing Muslimah & 61,2 & 70,7 & 9,5 & 15,52 \\
\hline 6 & Model Role Playing, Hasil Belajar IPS & 54,64 & 75,56 & 20,92 & 38,28 \\
\hline 7 & $\begin{array}{l}\text { Model Pembelajaran Kooperatif Bermain Eem Sulaemi } \\
\text { Peran (Role Playing) dan Hasil Belajar } \\
\text { IPS }\end{array}$ & 51,61 & 84,81 & 33,2 & 64,32 \\
\hline 8 & Hasil Belajar dan Teknik Bermain Peran $\quad$ Rossi Iskandar & 61,2 & 68 & 6,8 & 11,11 \\
\hline 9 & $\begin{array}{ll}\text { Aktivitas dan Hasil Belajar } & \text { Rini Meita Indrawati } \\
\end{array}$ & 78,93 & 80,24 & 1,31 & 1,65 \\
\hline 10 & $\begin{array}{llr}\text { Karakter Dan Hasil Belajar IPS, Metode } & \text { Achmad } & \text { Basari, } \\
\text { Bermain Peran } & \text { Wahyudi, } & \text { Siti } \\
& \text { Suardiman } & \\
& & \\
\end{array}$ & 66,5 & 72,92 & 6,42 & 9,6 \\
\hline 11 & $\begin{array}{l}\text { Model Pembelajaran Role Playing Hasil Arleni Tarigan } \\
\text { Belajar IPS }\end{array}$ & 66,84 & 88,68 & 21,84 & 32,67 \\
\hline 12 & $\begin{array}{lll}\text { Model Role Playing Dengan } & \text { Media } & \text { Eka Yuliana Sari, Inggrid } \\
\text { Video, Hasil Belajar IPS } & \text { Bela Suastiaji, Lintang } \\
& \text { Permata }\end{array}$ & 54,64 & 76,56 & 21,92 & 40,11 \\
\hline Mod & el Pembelajaran Role Playing atau bermain peran & 63,84 & 77,71 & 13,86 & 23,32 \\
\hline
\end{tabular}

Berdasarkan hasil analisis tersebut dapat dilihat bahwa model pembelajaran role playing atau bermain peran dapat meningkatkan hasil belajar dari mulai yang terendah 1, 65\% sampai yang tertinggi $64,32 \%$ dengan rata-rata $23,32 \%$. 
Kristin, F. / Jurnal Refleksi Edukatika 8 (2) (2018)

Tabel. 2 Paired Samples Statistics

Paired Samples Statistics

\begin{tabular}{rlrrrr}
\hline & & Mean & N & Std. Deviation & \multicolumn{2}{l}{ Std. Error Mean } \\
\hline \multirow{2}{*}{ Pair 1 } & Sebelum & 63.8483 & 12 & 8.20782 & 2.36939 \\
\cline { 2 - 6 } & Sesudah & 77.7492 & 12 & 6.64418 & 1.91801 \\
\hline
\end{tabular}

Tabel. 3 Paired Samples Correlations

Paired Samples Correlations

\begin{tabular}{rrrrrr}
\hline & N & \multicolumn{2}{c}{ Correlation } & \multicolumn{2}{l}{ Sig. } \\
\hline Pair 1 & Sebelum\&Sesudah & & 12 & .222 & .489 \\
\hline
\end{tabular}

Tabel. 4 Paired Samples Test

Paired Samples Test

\begin{tabular}{|c|c|c|c|c|c|c|c|c|c|}
\hline & \multicolumn{5}{|c|}{ Paired Differences } & \multirow[t]{3}{*}{$\mathrm{t}$} & \multirow[t]{3}{*}{$\mathrm{df}$} & \multirow{3}{*}{$\begin{array}{l}\text { Sig. }(2- \\
\text { tailed) }\end{array}$} \\
\hline & & \multirow[t]{2}{*}{ Mean } & \multirow[t]{2}{*}{$\begin{array}{c}\text { Std. } \\
\text { Deviation }\end{array}$} & \multirow[t]{2}{*}{$\begin{array}{l}\text { Std. Error } \\
\text { Mean }\end{array}$} & \multicolumn{2}{|c|}{$\begin{array}{l}\text { 95\% Confidence Interval } \\
\text { of the Difference }\end{array}$} & & & \\
\hline & & & & & Lower & Upper & & & \\
\hline Pair 1 & $\begin{array}{l}\text { Sebelum - } \\
\text { Sesudah }\end{array}$ & $13.90083^{-}$ & 9.34491 & 2.69764 & -19.83831 & -7.96336 & -5.153 & 11 & .000 \\
\hline
\end{tabular}

Tabel 2 di atas menunjukkan bahwa hasil belajar IPS dengan menggunakan model pembelajaran role playing atau bermain peran dapat meningkat dengan nilai rata-rata 63,84 menjadi 77,74. Tabel 3 menunjukkan ada relasi antara nilai rata-rata hasil belajar IPS siswa sebelum dan sesudah pembelajaran dengan menggunakan model pembelajaran role playing atau bermain peran.

Hasil uji hipotesis, Ho = tidak terdapat perbedaan yang signifikan hasil belajar IPS siswa sebelum dan sesudah pembelajaran dengan menggunakan model pembelajaran role playing atau bermain peran dan $\mathrm{H}_{1}=$ terdapat perbedaan yang signifikan hasil belajar IPS siswa sebelum dan sesudah pembelajaran dengan menggunakan model pembelajaran role playing atau bermain peran. Dari tabel 3 tampak bahwa nilai Sig $(0,00)$ $<\alpha(0,05)$ dan Tabel 4 menunjukkan bahawa nilai $\mathrm{t}_{\text {hitung }}=-5,153<\mathrm{t}_{\text {tabel }}=1,812$ maka Ho ditolak. Jadi dapat disimpulkan bahwa terdapat perbedaan yang signifikan hasil belajar IPS siswa sebelum dan sesudah pembelajaran dengan menggunakan model pembelajaran role playing atau bermain peran.

Berdasarkan hasil analisis penelitian dapat kita lihat bahwa model pembelajaran role playing atau bermain peran dari masing-masing penelitian dapat meningkatkan hasil belajar, meskipun dengan hasil yang berbeda-beda. Hal ini dipengaruhi oleh berbagai faktor, baik faktor dari dalam diri individu maupun faktor dari luar individu. Faktor dari dalam diri individu seperti faktor dari diri siswa itu sendiri, misal saat mengikuti tes kondisi siswa kurang sehat. Faktor dari luar individu misalnya dari lingkungan, kondisi sekolah, letak sekolah, dan subjek peneliti yang berbeda-beda.

\section{SIMPULAN}

Berdasarkan hasil analisis model pembelajaran role playing dapat meningkatkan hasil belajar siswa mulai dari yang terendah $1,65 \%$ sampai yang tertinggi $64,32 \%$ dengan rata-rata $23,32 \%$. Saran bagi penelitian selanjutnya agar lebih banyak menggunakan artikel yang diikutkan dalam penelitian meta analisis supaya data yang diperoleh lebih luas dan bisa dilihat lebih mendalam hasil penelitiannya.

\section{DAFTAR PUSTAKA}

Budiansyah, B. 2017. Penggunaan Metode Role Playing Untuk Meningkatkan Hasil Belajar Ilmu Pengetahuan Sosial Di Sekolah Dasar 
Negeri Palembang. JURNAL ILMIAH PGSD, 1 (02).

Christina, L. V., \& Kristin, F. 2016. Efektivitas Model Pembelajaran Tipe Group Investigation (GI) Dan Cooperative Integrated Reading And Composition (CIRC) Dalam Meningkatkan Kreativitas Berpikir Kritis Dan Hasil Belajar IPS Siswa Kelas 4. Scholaria: Jurnal Pendidikan dan Kebudayaan, 6 (3): 217230.

Dewi, R. P., \& Gunansyah, G. 2014. Penerapan Metode Pembelajaran Role Playing Untuk Meningkatkan Motivasi Dan Hasil Belajar Siswa Pada Pembelajaran IPS Di Sekolah Dasar. Jurnal Penelitian Pendidikan Guru Sekolah Dasar, 2 (3).

Ernani, E., \& Syarifuddin, A. 2017. Pengaruh Metode Role Playing Terhadap Keterampilan Berbicara Siswa Pada Mata Pelajaran Bahasa Indonesia Kelas V di Madrasah Ibtidaiyah Wathoniyah Palembang. JIP: Jurnal Ilmiah PGMI, 2 (1): $29-42$.

Indrawati, R. M. 2013. Peningkatan Aktivitas dan Hasil Belajar Materi Peristiwa Sekitar Proklamasi Melalui Bermain Peran. Journal of Elementary Education, 2 (1).

Iskandar, R. I. R. 2017. Peningkatan Hasil Belajar Siswa Melalui Teknik Bermain Peran Pada Mata Pelajaran IPS Pokok Bahasan Proklamasi Kemerdekaan. JURNAL PENDIDIKAN DASAR, 6 (2): 307-316.

Kristin, F. 2016. Analisis Model Pembelajaran Discovery Learning Dalam Meningkatkan Hasil Belajar Siswa SD. Jurnal Pendidikan Dasar Perkhasa, 2 (1).

Kristin, F. 2016. Efektivitas Model Pembelajaran Kooperatif Tipe STAD Ditinjau Dari Hasil Belajar IPS Siswa Kelas 4 SD. Scholaria: Jurnal Pendidikan dan Kebudayaan, 6 (2): 74-79.

Lestari, R. S. 2017. Pengaruh Penggunaan Model Role Playing Dengan Media Video Terhadap Hasil Belajar IPS (Studi Eksperimen Pada Siswa Kelas V SDN Gondangwetan Pasuruan). PEDAGOGY, 2 (1).
Muslimah, M. 2017. Upaya Peningkatan Hasil Belajar IPS Melalui Penerapan Metode Role Playing Pada Siswa Kelas III SDN 2 Gedongmulyo Kecamatan Lasem Kabupaten Rembang Tahun 2014/2015. DIDAKTIKA PGRI, 2 (2): 201209.

Muzakir, M. A. 2017. Meningkatkan Hasil Belajar Siswa Pada Materi Peristiwa Sekitar Proklamasi Kemerdekaan Indonesia Melalui Model Pembelajaran Role Playing Yang Divariasikan Dengan Student Teams Achievement Divisions (STAD) Di Kelas V SDN Kelayan Selatan 9 Banjarmasin. Jurnal Paradigma 9 (2).

Partami, N. P. I., Raga, G., \& Sudatha, I. G. W. 2013. Pengaruh Metode Bermain Peran Berbantuan Media Audio Visual Terhadap Hasil Belajar IPS Siswa Kelas IV SDN 1 Seririt. MIMBAR PGSD Undiksha 1 (1).

Sari, E. Y., Suastiaji, I. B., \& Permata, L. 2016. Pengaruh Penggunaan Model Role Playing Dengan Media Video Terhadap Hasil Belajar IPS (Studi Eksperimen Pada Siswa Kelas V SD Islam Al-Gontory Tulungagung). Jurnal Pendidikan dan Pembelajaran Anak Sekolah Dasar, 2 (01).

Suarsana, I. B. P., Lasmawan, W., \& Marhaeni, A. A. I. N. 2013. Pengaruh Metode Pembelajaran Bermain Peran Berbantuan Asesmen Kinerja Terhadap Hasil Belajar IPS Dan Motivasi Berprestasi Kelas V SDN Gugus II Laksamana Jembrana. PENDASI: Jurnal Pendidikan Dasar Indonesia, 3(1).

Sulaemi, E. 2018. Penerapan Model Pembelajaran Kooperatif Bermain Peran (Role Playing) Pada Mata Pelajaran Ilmu Pengetahuan Sosial Untuk Meningkatkan Hasil Belajar Siswa Kelas III Di SD Negeri Setragalih Kecamatan Cibogo Kabupaten Subang. Biormatika: Jurnal Ilmiah Fakultas Keguruan Dan Ilmu Pendidikan, 4 (1).

Tarigan, A. 2017. Penerapan Model Pembelajaran Role Playing Untuk Meningkatkan Hasil Belajar IPS Siswa Kelas III SD Negeri 013 Lubuk Kembang Sari Kecamatan Ukui. Primary, 5 (3): 102-112. 
Utami, S., \& Afandi, M. 2010. Upaya Peningkatan Hasil Belajar IPS Materi Mempertahankan Kemerdekaan Indonesia Melalui Metode Role Playing Pada Kelas V SD Negeri 02 Wiroditan Kabupaten Pekalongan.

Wahyudi, A. B. E., \& Suardiman, S. P. 2013. Meningkatkan karakter dan hasil belajar IPS menggunakan metode bermain peran pada siswa SD. Jurnal Prima Edukasia, 1(2), 113-123.

Wugarsari, Z. D. 2017. Penggunaan Metode Bermain Peran Melalui Pembelajaran Tematik Integratif Jenis Jaring Laba-Laba Untuk Meningkatkan Hasil Belajar Mata Pelajaran Pendidikan Kewarganegaraan, Bahasa Indonesia Dan Pendidikan Jasmani Olahraga Dan Kesehatan (Terintegrasi) Pada Siswa Kelas III. Karya Ilmiah Mahasiswa Progdi Pendidikan Guru Sekolah Dasar FKIP, 1(2).
Zahroul, C. 2017. Penerapan Metode Bermain Peran Untuk Meningkatkan Aktivitas Dan Hasil Belajar Siswa Kelas V Pada Mata Pelajaran IPS Pokok Bahasan Jenis-Jenis Usaha Ekonomi Di SDN Ngadiluwih 02 Kediri. PEDAGOGI, 2 (2).

Suwarno, A. 2017. Penerapan Metode Inquiry Terhadap Hasil Belajar Siswa Pada Mata Pelajaran IPS Terpadu Dalam Materi Keragaman Flora Dan Fauna Di Indonesia Di Kelas VII SMP Negeri 1 Tebas. REFLEKSI EDUKATIKA, 7(1): 1115. 